Cahiers $d u$ MONDE RUSSE

\section{Cahiers du monde russe}

Russie - Empire russe - Union soviétique et États indépendants

$43 / 4 \mid 2002$

Intellectuels et intelligentsia

\title{
Simon Doubnov, Le livre de ma vie
}

\section{Sylvie Anne Goldberg}

\section{OpenEdition \\ Journals}

Édition électronique

URL : https://journals.openedition.org/monderusse/4057

DOI : 10.4000/monderusse. 4057

ISSN : $1777-5388$

Éditeur

Éditions de l'EHESS

Édition imprimée

Date de publication : 30 décembre 2002

Pagination : 795-799

ISBN : 2-7132-1796-2

ISSN : $1252-6576$

\section{Référence électronique}

Sylvie Anne Goldberg, "Simon Doubnov, Le livre de ma vie », Cahiers du monde russe [En ligne], 43/4 I 2002, mis en ligne le 18 juin 2009, consulté le 03 septembre 2022. URL : http://

journals.openedition.org/monderusse/4057 ; DOI : https://doi.org/10.4000/monderusse.4057

Ce document a été généré automatiquement le 3 septembre 2022.

Tous droits réservés 


\title{
Simon Doubnov, Le livre de ma vie
}

\author{
Sylvie Anne Goldberg
}

\section{RÉFÉRENCE}

Simon DOUBNOV, Le livre de ma vie. Souvenirs et réflexions, matériaux pour

l'histoire de mon temps. Trad. du russe et annotations par Brigitte Bernheimer, préf. de Henri Minczeles. Paris, Cerf, 2001, 1177 p., préf. aux éd. précédentes, index.

1 Né dans la bourgade biélorusse de Mstislav le 10 septembre 1860, assassiné un jour de décembre 1941, pendant l'extermination du ghetto de Riga, Simon Doubnov est l'un des plus grands historiens du judaïsme. Son introduction en France, relativement tardive, doit beaucoup au travail de Renée Poznanski qui donna l'occasion au lectorat français de se familiariser avec sa pensée en publiant en 1989 une excellente traduction savamment annotée de ses volumineuses Lettres sur le judaïsme ancien et nouveau. Cette parution, précédée une année auparavant de son Histoire d'un soldat juif 1880-1915', fut peut-être à l'origine de «l'Association des amis de Simon Doubnow» qui permit aux éditions du Cerf de faire paraître son Précis d'histoire juive, puis son Histoire moderne du peuple juif ${ }^{2}$. On reste cependant redevable à Doubnov d'une somme considérable de travaux, dont une histoire universelle des juifs en dix volumes, une histoire des juifs en Russie et Pologne, ainsi qu'une histoire du hassidisme ${ }^{3}$, tous ouvrages destinés à combler les lacunes demeurant, à l'aube $\mathrm{du} \mathrm{xx}^{\mathrm{e}}$ siècle, dans l'historiographie des juifs de cette partie du monde.

2 Doubnov vécut en Europe orientale la période durant laquelle se déroulèrent les événements les plus déterminants de l'histoire contemporaine, jalons de toute l'histoire $\mathrm{du} \mathrm{xx}^{\mathrm{e}}$ siècle. Si la vie de ce très grand historien juif recouvre, en effet, un pan crucial de l'histoire mondiale, pour ce qui est de l'histoire des juifs en particulier, elle s'inscrit dans un processus de destruction dont l'inéluctabilité n'apparait qu'a posteriori. Les carnets et la correspondance qui étayent la rédaction du Livre de ma vie servent de trame à l'agencement de ces mémoires entamées en 1921 et rédigées au cours des vingt années suivantes. Les matériaux varient cependant au cours du temps et si certains chapitres 
relèvent de la mémoire familiale et personnelle de Doubnov, d'autres reprennent des notes brèves, directement tirées de ses carnets, tenus sa vie durant. L'ouvrage en luimême, dont le format copieux pourrait rebuter, tient à la fois du récit initiatique et du document historique. En ce sens, le sous-titre, Matériaux pour l'histoire de mon temps, tient largement ses promesses et bien plus encore: il permet de percevoir comment les espérances et les rêves de tout un peuple se sont heurtés à la brisure du $\mathrm{xx}^{\mathrm{e}}$ siècle. La traduction en langue française de cet ouvrage - qui devrait devenir un classique ou, mieux encore, un livre de chevet - comble une lacune considérable. En effet, la plupart des ouvrages existant sur ce pan de l'histoire des juifs sont parus soit en yiddish, soit en hébreu, soit en anglais. La documentation qu'il contient est considérable d'un point de vue historique, mais, présentée par un de ses acteurs les plus engagés, elle est de surcroît une matière vive.

3 Il est certes impossible de rendre compte de ce millier de pages sans tomber dans une forme anecdotique qui ne lui rendrait pas justice. L'ouvrage, en mêlant intimement les éléments biographiques aux événements (et il n'en manque guère) de la grande histoire, leur prêtant ainsi corps et chair, permet au lecteur non seulement de rencontrer avec émotion les grandes figures du panthéon juif de l'Europe orientale mais aussi de s'introduire subrepticement dans tous les débats intellectuels et idéologiques qui ont traversé le siècle.

4 Entamée en 1921, au moment où Doubnov estime avoir franchi les principales épreuves de sa vie et avoir accompli sa tâche, cette autobiographie vise à en retracer les étapes et à faire une synthèse des événements qui ont marqué son siècle, autant qu'à rendre compte du combat qu'il a mené avec ses contemporains pour améliorer le sort de ses coreligionnaires. C'est avec tendresse qu'il décrit la bourgade qui l'a vu naître, et où il ira, tant qu'il le pourra, se ressourcer régulièrement. Son grand-père, ses parents et maitres apparaissent tels des images d'Épinal, archétypes d'une société juive traditionnelle où le combat quotidien pour gagner une maigre subsistance recouvre toute autre préoccupation à l'exception du respect de la Sainte Torah. Le mémorialiste, en revenant sur son enfance, se décrit comme décidément réfractaire à l'étude talmudique - trop aride à son goût -, et avec son frère pour complice en bibliomanie, il dévore tout ouvrage susceptible de lui tomber sous la main. L'élargissement de son regard sur le monde passera ainsi par des lectures «coupables ", qui lui permettront de s'initier aux premiers écrits de la Haskala, encore rédigés dans un hébreu quasi biblique, et à la littérature russe. Ses tentatives de scolarisation russe le mènent jusqu'à l'école du district, mais le diplôme de fin d'études destiné à lui ouvrir les portes de l'université restera inaccessible. C'est en autodidacte qu'il parachèvera une formation qui le conduira à collaborer aux foisonnantes revues judéo-russes de l'époque. S'il se fait les dents dans Russkji Evrej, le jeune Doubnov ne tardera guère à publier dans Rassvet, puis dans le grand mensuel de l'intelligentsia Voshod ${ }^{4}$, auquel il restera lié un quart de siècle durant, y publiant des chroniques littéraires qui le font connaître et parfois redouter des plumitifs de tous bords, puis les ébauches de ses livres. En séjour clandestin dans la capitale, SaintPétersbourg, Doubnov y établira de solides amitiés qui lui permettront, le moment venu, de s'insérer dans les mouvements d'avant-garde de sa génération en quête d'identité autant que de liberté. Dans une Russie qui interdit aux juifs la libre circulation et a fortiori la libre installation hors de la zone de résidence, il n'est guère étonnant de les voir errer de ville en ville, s'établissant clandestinement chez les uns ou les autres jusqu'à ce qu'un arrêt les renvoie dans leur bourgade provinciale d'origine. Il est peu de dire que, pour les juifs de la Sainte Russie, les années qui succèdent aux pogromes de 1881 
sont des années de plomb, marquées par la constance des politiques judéophobes. Oscillant entre le giron natal et Saint-Pétersbourg où il travaille, c'est temporairement à Odessa que Doubnov trouvera un refuge pour y loger en compagnie de sa famille.

5 À vrai dire, ce refuge se révélera un havre pour l'historien, lui permettant, grâce à un environnement intellectuel riche, de développer amplement ses théories politiques ainsi que de peaufiner sa méthode historiographique, tout en donnant le meilleur de lui-même dans ses activités littéraires. L'intelligentsia d'Odessa comprend, dans les années 1890, des personnalités illustres : Ahad ha-Am, Hayim Nahman Bialik, Mendele Moykher Sfoyrim, Sholem Aleykhem, Lilienblum, Berdishewski en font alors partie. Palestinophiles militants, assimilationnistes convaincus et tenants d'une renaissance populaire, nationaliste et yiddishisante débattent alors régulièrement, de vive voix ou à travers leurs articles ou dans des rencontres publiques. C'est dans ce cercle chaleureux que Doubnov en vient, graduellement, à se considérer comme un «missionnaire de l'histoire" dont la vocation est de "diffuser les connaissances historiques sur le judaïsme» (p. 343 sq.). Engagé à fond dans cette entreprise, Doubnov désapprouve aussi bien l'aspiration des sionistes qui, selon lui, voudraient faire tourner «la roue de l'histoire" en sens inverse, empruntant une voie qu'il juge "étroite», que les engagements des bundistes qui s'attachent plus à la cause ouvrière qu'à la cause nationale juive. Selon lui, seule une politique de souveraineté nationale permettrait au peuple juif de maintenir son unité, en dépit de la dispersion ${ }^{5}$. Afin de réduire ses activités publiques, Doubnov décide de migrer vers Vilna. Les valises sont faites lorsque survient la nouvelle du pogrome de Kishinev, en 1903. Doubnov vient d'assister à une conférence donnée par un jeune homme talentueux, mais dont il estime l'idéologie sioniste "bornée »: il s'agit de Vladimir Jabotinsky, qui défend alors l'idée de la fin de la judéophobie par une renaissance politique (p. 502) ${ }^{6}$. Le soir même, le cercle de Doubnov comprenant, outre celui-ci, Bialik, Ahad ha-Am, pour ne citer que les écrivains les plus célèbres, décide de mettre sur pied des groupes d'autodéfense ${ }^{7}$. À partir de 1897, la vie politique se fait plus bouillonnante, le programme lancé au premier congrès sioniste de Bâle retentit dans la rue juive, la conduisant - dit alors Doubnov - « à s'abandonner à l'ivresse du messianisme » (p. 412).

6 Juché sur la crête d'un volcan en constante éruption, continuellement déchiré entre son désir de s'enfermer dans l'écriture de l'histoire du temps passé et l'engagement dans les nécessités immédiates, Doubnov poursuit néanmoins la double mission qu'il s'est assignée. Un parti politique, le Volskpartei, fondé sur la théorie autonomiste du nationalisme culturel qu'il a élaborée, verra le jour en novembre 1906. Après la célèbre conférence de Czernowicz qui avait prononcé la suprématie du yiddish, en septembre 1908, la question des langues nationales se place au centre des débats : yiddish, hébreu, russe? Quelle langue nationale officielle adopter ? Si Doubnov défend l'adoption du principe trilingue en vertu de la préservation des droits historiques et culturels de tous les membres du peuple juif, ses positions sont loin de faire l'unanimité. C'est dans le cadre de la Société d'histoire et d'ethnographie ${ }^{8}$ que Doubnov associera histoire et politique. Ses publications se partagent désormais entre le mensuel littéraire Everjiskij mir et la revue trimestrielle scientifique Evrejskaja starina $a^{9}$. Une fois la guerre déclarée, Doubnov tente, en se jetant dans l'écriture, de surmonter l'effroi que suscitent les nouvelles venues du front, et notamment des régions juives. Les Polonais affirment que les juifs espionnent pour le compte des Autrichiens, et à l'hécatombe des zones de combats s'ajoutent les victimes des pogromes, expulsés et déportés qui ne peuvent se chiffrer. Pourtant, en ce temps où les informations n'apportent que des récits d'atrocités, 
où ne pointe nulle trace d'espoir ou d'embellie, et où tout oppresse le présent, Doubnov spécule sur l'avenir, qui permettra aux juifs de revendiquer leurs droits, lors de la conférence de paix qui suivra inévitablement l'issue de la guerre (p. 714). Traqué par la censure, il travaille néanmoins, inlassablement, à la publication simultanée de son œuvre en hébreu, en yiddish, en allemand et en anglais, par delà les frontières de sa geôle russe. Il s'en explique en ces termes dans ses carnets, le 18 mars 1915: "Pour moi, l'histoire était une source de vie bouillonnante, de combat, de création d'esprit vivant, l'origine d'une conception du monde, la vénérable légende des siècles » (p. 717).

Pourtant, Doubnov, profondément bouleversé par le pogrome de Kishinev, avait écrit : "Que pouvions-nous attendre d'autre après vingt-deux ans, pendant lesquels "chaque jour tuait un rêve" ? (p. 508).

On conclura sur cette phrase, en se contentant de mentionner la litanie des événements qui vont se succéder dans un tempo infernal: révolution de 1905, représailles, déportations, Première Guerre mondiale, révolution de 1917, guerre civile, victoire des bolcheviks... S'il ne s'agissait du grand historien, on aurait pu dire que son destin aura connu le sort ordinaire des juifs de sa génération. Survivant à la famine, à la maladie et aux massacres de la guerre civile, Doubnov ira, comme nombre de Russes, trouver refuge dans le Berlin de la république de Weimar. Rattrapé une fois encore par le crépuscule de l'histoire, il croira échapper à Hitler en s'installant à Riga... Las! le vieillard de 81 ans sera abattu d'une balle, en trébuchant sur l'échelle qui devait le conduire, en autobus, vers les gaz. Son œuvre demeure. Dans l'étrangeté du temps, la discussion qu'il a ouverte à propos des idéologies nationales juives et de la succession des cycles de rayonnement et de déclin dans l'histoire des juifs, prend parfois, à la lueur de l'actualité, une sombre acuité.

\section{NOTES}

1. S. Doubnov, Lettres sur le judaïsme ancien et nouveau, trad. du russe, annoté et présenté par Renée Poznanski, Paris, Cerf, 1989 (Saint-Pétersbourg, 1907 et Tel-Aviv, 1937) ; id., Histoire d'un soldat juif 1880-1915 (Petrograd, 1917), trad. par Laurence Dyevre et Alexandre Eidelman, Paris, Cerf, 1988.

2. S. Doubnov, Précis d'histoire juive : des origines à 1934 (Paris, 1936), trad. par I. Pougatz, Paris, Cerf, 1992 ; id., Histoire moderne du peuple juif (Paris, 1933), trad. par B. Bernheimer, Paris, Cerf, 1994.

3. S. Doubnov, Weltgeschichte des Jüdischen Volkes, Berlin, 1937 ; id., History of the Jews in Russia and Poland, 3 vols, Philadelphie, 1946 ; id., Geschichte des Chassidismus, Berlin, 1931 (hébreu : Tel Aviv, 1930-19331).

4. Périodique publié à Saint-Pétersbourg de 1881 à 1906.

5. Voir dans S. Douvnov, Lettres sur le judaïsme, op. cit., la lettre X, «D'une intelligentsia à la dérive ", ainsi que la lettre XIII, «De la suprématie d'une politique nationale dans la vie d'une nation opprimée ».

6. Jabotinsky deviendra le dirigeant du mouvement sioniste radical révisionniste. 
7. Le texte de l'appel, rédigé en hébreu par Ahad ha-Am pour éviter la censure, rentrera dans l'histoire. Ha-tekufa, 25, 1928, pp. 416-420.

8. Fondée à Saint-Pétersbourg en 1908, après que Doubnov eut appelé de ses vœux un tel projet en 1891.

9. Les dix premiers volumes furent édités par Doubnov entre 1908 et 1918, les trois derniers (1924-1930) par un collectif éditorial. Evrejskij mir paraîtra jusqu'en 1912. 